\section{Cancer institute treated unfairly}

SIR - Your report (Nature 368, 89; 1994) of research-related budget allocation by the Higher Education Funding Council for England (HEFCE) for the years 1994 95 states that only two universities Oxford and Cambridge - have been capped. The report is incomplete: the Institute of Cancer Research, a member of the British Postgraduate Medical Federation of the University of London, has also been capped, severely so.

The institute has been a higher education institution (HEI) for more than 40 years, but until recently was excluded from funding by HEFCE, or HEFCE's predecessors, for reasons that have been historical rather than rational. This anomaly was corrected in August 1993, when HEFCE funding of $£ 2.4$ million per annum commenced following ministeria transfer of exactly that amount from the budget of the Medical Research Council (MRC) to HEFCE. The sum involved was that contributed at the time by government (MRC) to the institute.

The MRC, despite this raid on its budget, treats us exactly as all other HEIs: grant applications are received and, when they are successful in competition against others, grants are awarded. Not so HEFCE. Despite our excellent research performance in the 1992 University Funding Council Research Assessment Exercise, our HEFCE grant is pegged at $£ 2.4$ million a year, with not a penny for $\mathrm{PhD}$ students, of whom we have 60 .

Our total annual budget is $£ 23$ million, and our average competitively won grant income per academic staff member, of whom there are 80 , is probably the highest in the United Kingdom. The imbalance between the two limbs of our dual support is as unsustainable as it is indefensible, yet HEFCE offers no reconsideration before completion of the next (and delayed) research assessment exercise in 1996-97. In the meantime, HEFCE continues to profess its commitment to competition and to selectivity based on excellence and spends more than $£ 500$ million per annum on uncapped or even protected research support for HEIs that came below us in the 1992 assessment exercise. If HEFCE has a responsibility to use public funds for infrastructural support of the best available research in the higher education sector, then that responsibility is clearly capable of being better discharged.

\section{Peter Garland}

(Chief Executive)

Institute of CancerResearch:

Royal Cancer Hospital,

Fulham Road

London SW3 6JB, UK
Sex determination

SIR - A leading article (Nature 361, 283; 1993) argued that a service for sex determination offered by a London clinic was so unreliable that it did not justify a debate on novel "serious ethical questions". Since then, it has become possible to identify the sex of human preimplantation embryos after in vitro fertilization (IVF). In our opinion, that is a serious development.

Although the use of IVF for nonmedical sex selection is held by some to respect a woman's autonomy, we hold that sex is not a disease and that sex selection is not a condition that justifies the use of invasive procedures. In our view, although woman's autonomy should be respected most of the time, clinicians, in accordance with reasonable professional standards, must refrain from actions that might impair rather than promote the interests of the patient.

The use of IVF for sex selection is a misuse of costly medical resources, at least so long as there are women who need this service, and who cannot afford it. But it is also troubling that the use of IVF for sex selection might establish a dangerous precedent.

That, in our opinion, is why IVF should be used for medical purposes only. It is not the idea of sex preselection in general that we oppose. If there were a simple noninvasive technique for sex selection not requiring the active intervention of medical staff and costly medical resources, then every couple would have the right of selection. But while sex selection is determined by IVF, the use of this technology by medical personnel for nonmedical purposes raises serious ethical questions.

\section{Asher Shushan}

Josef G. Schenker

Department of Obstetrics and

Gynaecology,

Hadassah Medical Organization,

Kiryat Hadassah,

POBOX 12000 ,

Jerusalem 91120, Israel

\section{Academic research a dirty word?}

SIR - I was interested in Daedalus's suggestion ${ }^{1}$ that gases might be stored in a molecular sponge. Our recent work on zeolites $^{2,3}$ (not polymers in the sense implied by Daedalus) has produced strong evidence that some zeolites behave in a not dissimilar way under the stress of physical adsorption. In the physical adsorption of argon and nitrogen into silicalite, for example, the pores first of all fill to their maximum capacity and then the framework expands to accommodate an extra 30 per cent of the adsorbate. This interpretation of experimental adsorption isotherms originated from simulation studies, and has been confirmed by very recent neutron scattering work (N. J. M. Tosi-Pellenq \& J.-P. Coulomb, personal communication). Unfortunately, our proposal to extend this investigation by studying the conditions under which adsorbent frameworks might distort during adsorption did not receive support from the Science and Engineering $\mathrm{Re}$ search Council. The referee commented that the work was "academic" and of no industrial significance. Perhaps the farsighted research managers of DREAD$\mathrm{CO}$ might care to contact me to discuss this project.

\section{David Nicholson}

Department of Chemistry,

Imperial College of Science,

Technology and Medicine,

London SW7 2AY, UK

1. Jones, D. Nature 367,518 (1994)

2. Pellenq, R. J.-M. thesis, Univ. London, 1994

3. Pellenq. R. J.-M. \& Nicholson, D. Proc. COPS III Meeting, Marseille, 1993 (in the press).

\section{Freedom of proof}

SIR - Vladimir Koliadin (Nature 367, 406; 1994) offers a good insight on the danger of "democratic centralism" in the scientific establishment. However, he asserts that " $(t)$ he best way to proceed is not to try to 'prove' or 'disprove' a theory, but to concentrate attention on the positive aspects of any theory". I suggest, rather, that there should be no hindrance to complete freedom of any scientist to try to 'prove' or 'disprove' any theory, or to examine either 'positive' or 'negative' aspects of any theory. All opposition or hindrances to this total intellectual freedom of every individual scientist constitute 'politically correct science', which surely should be odious to every scientist. Robert E. Kofahl

1322 E. Wilson Avenue, Glendale, California 91206, USA

\section{Early 'cruise'}

SIR - The Second World War German V-1 was not a rocket (Nature 367, 424; 1994) but a jet-propelled pilotless aircraft. The next generation of terror weapons, the V-2, was an authentic rocket.

My recollection of the $\mathrm{V}-1$ is vivid because one fell near me in England in 1944. The 'buzz-bomb' flew with a characteristic flutter until the engine shut off, and then it dived to Earth. (During this interval one held one's breath.)

\section{Maxwell Gordon}

Aji-Pharma USA, Inc.,

500 Frank W. Burr Boulervard,

Teaneck, New Jersey 07666, USA 